\title{
Electronic transformation of government in the U.K.: a research agenda
}

\author{
Zahir Irani ${ }^{1}$, \\ Tony Elliman ${ }^{2}$ and \\ Paul Jackson ${ }^{3}$
}

${ }^{1}$ Brunel Business School, Brunel University, West London, U.K.; ${ }^{2}$ School of Information Systems and Computing, Brunel University, West London, U.K.; ${ }^{3}$ CIPFA Performance Improvement Network (PIN), Chartered Institute of Public Finance and Accountancy, U.K.

Correspondence: Zahir Irani, Brunel Business School, Brunel University, Uxbridge, London, UB8 3PH, U.K.

Tel.: + 44 (0) 1895 266054;

Fax: + 44 (0) 1895 269770;

E-mail: Zahir.Irani@Brunel.ac.uk
Received: ••

Revised: ••

Accepted: 3 August 2007

\begin{abstract}
This paper presents the findings of an exploratory research project into future e-Government (electronic Government) initiatives. The Virtual Institute for Electronic Government Research (VIEGO) project aimed at identifying and further developing the research agenda of e-Government based on a solid practical ground. As such, the paper offers a novel methodology in identifying the road map for future e-Government initiatives based on a series of workshops organised around the U.K. hosting a mixture of stakeholders involving both academics and parishioners. The analysis of the VIEGO workshops depicted that an e-Government research agenda involves a combination of social, technological and organisational issues at both governmental and individual citizen level, ultimately driven by empirical case-based experience and active participation in e-Government processes. Unlike other propositions for the future of e-Government offered in the eGovernment literature, raised research questions not only originated from an analysis of e-Government literature but also on the outcome of brainstorming, reflections and contemplations throughout the duration of the project.
\end{abstract}

European Journal of Information Systems (2007) 0, 000-000. doi:10.1057/ palgrave.ejis.3000698

Keywords: electronic government; report; VIEGO; survey; research agenda

\section{Introduction}

According to a report by the Interchange of Data between Administrations (IDABC), the U.K. is the biggest spender on public sector IT in Europe (EC, 2005a), spending $1.14 \%$ as a proportion of GDP on ICT investments, while the European average is $0.8 \%$. The report indicates 'sharp' differences between the nature of the spending in the U.K. and other European countries as the U.K. public sector spends around $40 \%$ more than the German or French. This is due to its huge investments in e-Government (electronic Government) and back office infrastructure.

Current e-Government initiatives have reached a stage of maturity in that mandates set by Central Government have been achieved, at a cost of $£ 184$ per household, over a 7-year period from 2001-2008. This equates to a total e-Government expenditure of $£ 3.9$ billion between 2001-200. In context, U.K. local authorities are expected to deliver a total of $£ 1.2$ billion in accumulated efficiency savings by 2007-2008 through realising the benefits of e-Government (EC, 2005b). Gershon (2004) calls in his report for $£ 21.5$ billion in annual efficiency improvements across Government by 2007-2008. The exploitation of e-Government such that benefits can be realised is the rationale being used to define transformational Government, within referred to as t-Government.

Lately, worldwide research on e-Government focussed on various aspects spreading through e-Government implementation (Singapore), perceived 
usefulness (the Netherlands), resistance and support (Global), performance assessment (India), quantitative evaluation (Italy), impact of e-Government (U.S.A.) and CRM (Singapore) to name a few. Yildiz (2007) reviewed the literature surrounding e-Government research and highlighted limitations and ways forward with no empirical evidence other than his own review to support such propositions. In contrast, project Virtual Institute for Electronic Government Research (VIEGO) provides solid background for the initiatives it presents, arising not only from literature surveys and analysis but also from the actual surveys and analysis, but from the actual requirements and views of practitioners (i.e. developers and users) of e-Government systems. The use of workshops as a methodology to gain access to the actual needs and future directions of e-Government is what makes the outcome of this paper stand out from other similar attempts.

\section{Rationale}

The initial activity for the VIEGO has been driven by the need to identify relevant key areas for future research in e-Government. Much of the growth in e-Government systems has been driven by a national or international political agenda to achieve significant implementation within a relatively short time-scale. Thus in 2006, there was thus a perceived need to take stock of this achievement (Elliman et al., 2007a). VIEGO departed from the existing e-Government research by placing particular emphasis on field data for the definition of its research themes rather than relying exclusively on those found in the relevant academic discourse. The vision was to create a virtual research institute that will address the most relevant problems by bringing together academics from many disciplines in different U.K. universities.

The VIEGO phase one project was run by the Information Systems Evaluation and Integration Group (ISEing) at Brunel University; funded by the U.K.'s Engineering Physical Sciences Research Council (EPSRC) and supported by the Chartered Institute of Public Finance and Accountancy (CIPFA)'s Improvement Through Technology Network. With its aim to widen the breadth of the e-Government research agenda and to expose critical themes for future research VIEGO did not seek to assess the current state of the art or to determine whether research unknown to the workshop participants already available. It focussed on setting out the critical research themes that the contributors considered to be key questions for the future of e-Government.

\section{Methodology}

The main research tool employed for the realisation of VIEGO's research objectives has been the organisation of consultation workshops. Five VIEGO workshops were organised around the U.K. (two in London and one each in Cardiff, Manchester and Edinburgh) to consult with different groups of stakeholders concerning their views on current e-Government initiatives, as well as on issues and topics they considered to be important for practice in the future.

The workshops were carefully organised to be a structured discussion with the researchers putting a minimum of content into the discussion. This was done to ensure that the findings arise from the stakeholders concerns rather than those of the VIEGO staff. One team of researchers led the discussion while another group was making a record of the debate. One of the major difficulties faced by the VIEGO researchers related to the capturing of unbiased individual inputs without ignoring group dynamics. The VIEGO research team used the cards technique in order to balance these objectives.

Immediately after an introduction to the main objectives of the consultation workshop, blank cards were distributed to the participants. Each participant was asked to write on separate cards short descriptions of the issues they regarded as the most important in the area of e-Government (see Figure 1).

The facilitator then organised the cards into apparently related groups and invited those present to review the grouping. They were free to shuffle cards between groups, create new groups, re-title them or add further cards until they reached some sort of consensus. Once this stage was completed, the issues on the cards were presented to the participants. By doing this, the group had the opportunity to reflect on individual opinions without each member being influenced $a$ priori from the opinions of the rest of the participants.

At this point, some issues raised in previous workshops were briefly introduced. A minimum of common understanding was deemed necessary for a meaningful dialogue between the various stakeholders. Hence, after the completion of the first workshop the participants were provided with a list of agreed working definitions that were used as a basis for further discussion (see the VIEGO report - Irani \& Elliman, 2007). The definitions themselves were the product of the workshops and were amended or extended during the course of the project. In certain cases, the definitions were also a starting point for

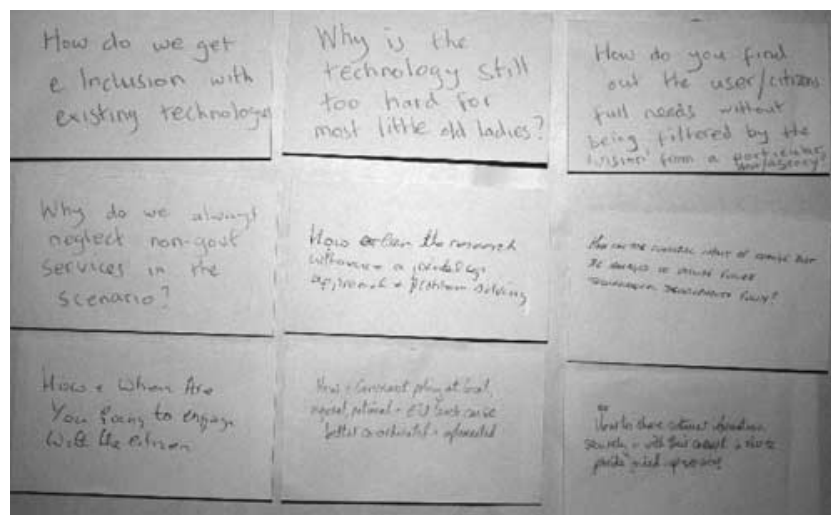

Figure 1 Some of the 32 initial issues cards from workshop 1. 
a debate where the participants contested and debated their validity.

In the second part of the exercise, each cluster of cards was taken and discussed in more detail. These discussions produced additional notes on flip charts.

In all 115 such initial statements cards and over 20 flip chart pages were obtained from the five workshops. Most of the discussion was also audio recorded and at least one of the recording team was making contemporaneous notes at any one time.

This collection data was subsequently analysed in a three-stage process:

(a) In the first stage the discussion was presented as a narrative.

(b) Next, all the relevant themes and the level of each individual's participation was counted and further analysed to create hierachical tables of the critical issues (Irani \& Elliman, 2007).

(c) Finally, the key themes and their interrelation were represented diagrammatically as a set of maps or schemas (Irani \& Elliman, 2007). Two of these maps are discussed in more detail in Elliman et al. (2007b).

\section{The participants}

The attendees for each workshop were self-selecting groups responding to open invitations to attend. These invitations were distributed through the CIPFA and SOCTIM networks of e-Government practitioners and to public sector members of ISEing.

The themes identified in different workshops were greatly influenced by the composition of the groups. The VIEGO consultation meetings were particularly careful to get input from a wide spectrum of representatives from different types of stakeholders, as shown in Figure 2.

The first workshop, held in London, had possibly the most diverse composition ranging from managers, public sector employees and independent consultants to local government officials, academics and local governmentelected representatives. Subsequent workshops had more focussed groups. The second workshop in Cardiff comprised almost exclusively of Welsh assembly and local government managers. Their interests were particularly focussed on issues of e-Government evaluation and measurements. In the third workshop, held in Manchester, the participants were primarily managers and IT experts with interests related to technological and organisational issues.

The fourth workshop in Edinburgh had participation from the Scottish Executive but was the one where academics had a predominant presence and the issues dominating the discussion were of a more fundamental nature; for instance, the definitions themselves were questioned and the issue of participation appeared in a variety of forms.

Although the intention was to avoid established academic views in favour of a more direct stakeholder input, academic colleagues aware of VIEGO were among

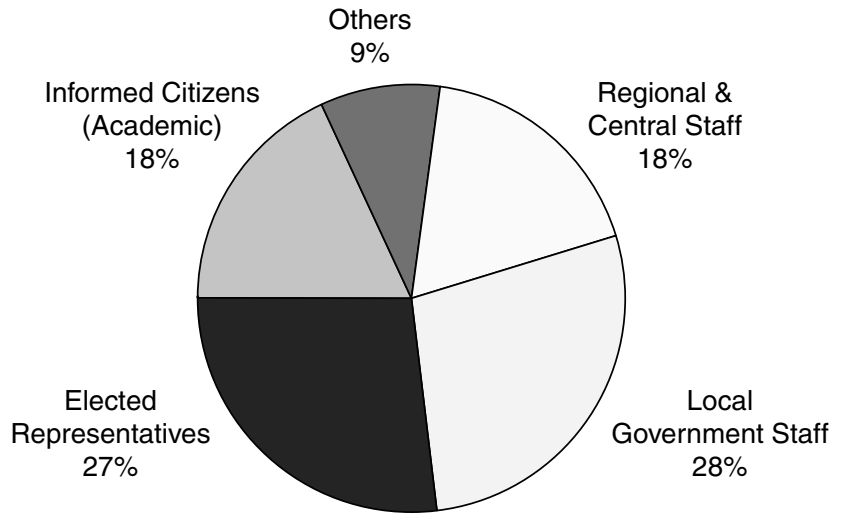

Figure 2 VIEGO participants by stakeholder type.

the most enthusiastic participants. This was accepted on the understanding that their role in the workshops was to listen and to participate as informed citizens rather than representatives of academia.

In the final workshop, again held in London, there was a deliberate attempt to get a view from the position of elected representatives and the workshop invitation was circulated to about 2,000 elected members in the London area. Thus, most participants were elected representatives from local government and as such were interested in how e-inclusion and participation could influence the decision-making process and the role of elected representatives in particular. Figure 3 shows the perspectives of each workshop moved around the core e-Government theme.

In the following sections of this paper, we present these findings followed by the conclusions drawn from them.

\section{The findings}

The VIEGO workshops demonstrated that an e-Government research agenda involves a combination of social, technological and organisational issues at both governmental and individual citizen level. This was ultimately driven by empirical case-based experience and active participation in e-Government processes as defined in Figure 4. It was sought to classify e-Government terminology through grouping it as either technical, social or organisational. This allowed for more specific factors to emerge within such groupings.

The analysis shows that a multi-disciplinary approach is essential to the investigation and research of eGovernment phenomena. This must involve a deep understanding and management of systems, information, policies, processes, security and change. An inherent and vital component underpinning these three facets of e-Government research undoubtedly involves the relationship between government bodies and the citizen, the development and growth of which defines the future trajectory of this field. 


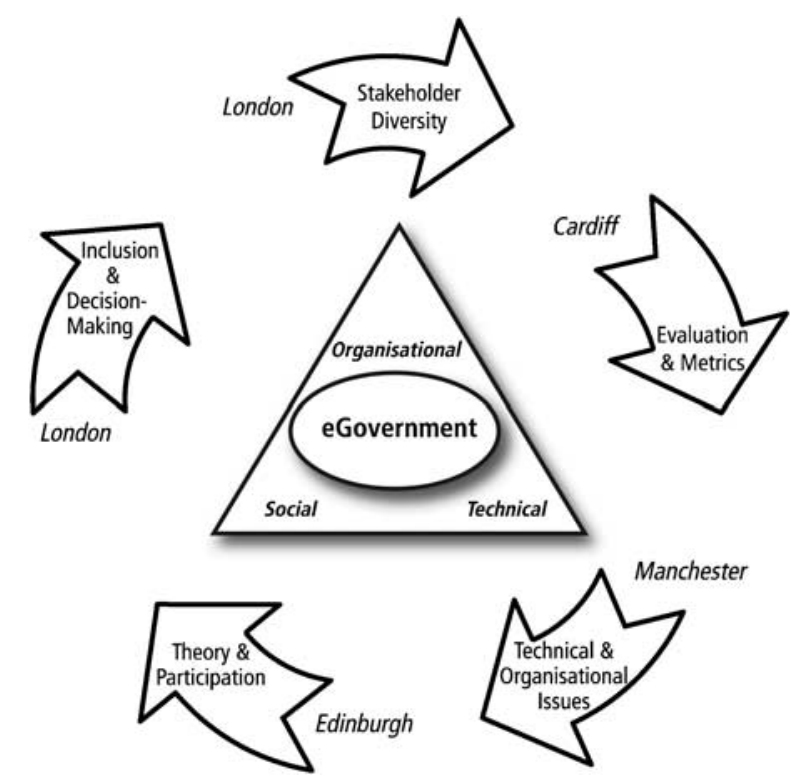

Figure 3 VIEGO workshop focus themes.

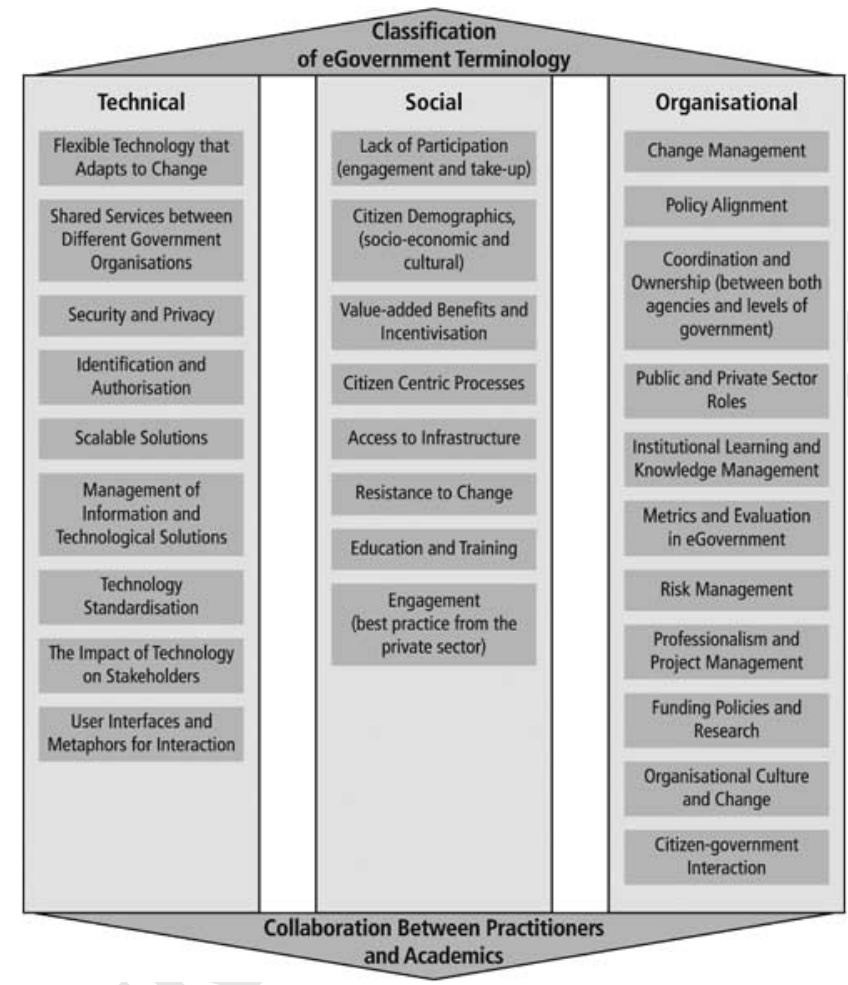

Figure 4 Key themes within the e-Government research agenda.

There was a widespread interest in the development of technologies and policies for e-Government among the contributors; in particular, there was an explicit focus on future developments and change. Many of them emphasised that the only constant feature in any e-Government-related service is constant change.

Although the political rhetoric has seen technology as a solution, it tended to surface quite often as the creator of problems rather than a solution. The key issues that emerge from the debate are about the fit of technology with business processes rather than developing the right technology.

There was a lack of clarity regarding the definition of fundamental e-Government concepts and a substantial part of the debate involved the identification and clarification of notions such as e-Participation, onestop-shop service provision and what constitutes an e-Government service.

As indicated above (Figure 4), the findings covered over 19 Technical, 20 Social and 65 Organisational research questions (Irani \& Elliman, 2007). This highlights the depth and complexity of e-Government research and practice. Although the classification is particularly useful for analytical purposes; the issues placed under each thematic heading are closely interlinked to ones in other categories. For instance, the issues of technological change and the need for flexible e-Government services are technological ones, but they are rooted in constant social change and require a certain organisational response.

The themes identified within each area can be broken down as follows:

\section{Technological research themes}

The main issues identified in the technical area related to

- the need for flexible and scalable technology,

- privacy and security of available services,

- shared services (including common identity management),

- standards, coordination and integration between government services and departments,

- identification and authentication and

- impact analysis - whether on citizen or organisation

The problem of scalability and flexibility of ICT systems and processes was one most often cited across the workshops. The drive to transform government and moves to foster innovation make this more acute. There is a fundamental need to understand how to create flexible systems that can adapt and change with demand. The constantly changing nature of e-Government services also meant that accessibility versus information security is an important issue. There was no consensus regarding the nature of what constitutes good or appropriate 'access' to information within e-Government as such.

The issue of how shared services can be managed both technologically and organisationally has been another very strong theme in this area. Multiple facets of this problem were discussed during the consultation workshops, ranging from purely technical (the management of shared databases) to organisational (how the 
administration structure is affected) to financial (such as whether there is return on investment for shared services projects). Not surprisingly, debates about shared data and appropriate access also identified the twin but distinct issues of privacy and security, and identification and authentication.

In the same vein, a predominant technological theme in all consultations was the issue of technical interoperability and standardisation. The issues raised were around how different department's projects may be managed, the technical tools needed for integration and in particular data or services standardisation.

The issues of open standards and open source software were also discussed. Stakeholders were unclear about the complexity and consequences of such developments but saw the need for further investigation of their impact.

The emphasis was often on the impact of technology rather than the technology itself. Questions such as the respective roles of local and central government, education in the use of IT and the potential for positive impact on the environment were raised. However, there were also concerns about the trend to dehumanise interaction between citizens and government.

\section{Social research themes}

The main issues identified under the social heading related to the citizen and civil society. They included

- engagement with citizens, government authorities and other stakeholders; considering 'social value added',

- the need for a citizen-centric process,

- take-up of e-Government services and incentivisation and

- diversity of different socioeconomic and cultural factors within citizen groups.

The question of how to engage stakeholders and manage social interactions and communications was a predominant concern under this heading. Different opinions concerning what constitutes 'participation' or engagement in e-Government highlighted the general need for clear definitions.

A central concern was to put the citizen in the centre of the e-Government process. This relates to both asking the citizen how they envisage the future of e-Government and how they would like demographic data to be handled. On more than one occasion, participants asked where was the evidence of citizen demand for eGovernment?

This request illustrates another dichotomy - the distinction between citizens and other stakeholders. There is a clear need to map out the pattern of stakeholders in e-Goverment and assess the legitimacy, urgency and weight that should be attached to the different groups.

The issue of creating incentives was presented as the primary means for encouraging citizens and other stakeholders to use e-Government services. Several approaches to the problem, ranging from technological solutions (such as multiple delivery channels) to policy approaches (such as making a focussed effort to engage stakeholders) were postulated. However, most of the evidence is anecdotal. Seeking to learn from the most popular existing and historical e-Government initiatives, by investigating key motivators for each stakeholder group, may thus provide a catalyst for future research.

All these efforts to engage various stakeholders need to be examined in the face of the resistance to change. There is a need for education not only as an encouragement to the take-up of services but also as a desired result of e-Government initiatives. The question of building trust to manage and overcome resistance to citizen-government interaction is also crucial. It is important to realise that those most in need of government services are those that are most likely to lack the confidence, training or opportunity to make the best use of them online.

Finally under this heading, participants identified the critical need for future e-Government research to acknowledge cultural diversity within the U.K. and the impact that such diversity should have upon the way research is designed.

\section{Organisational or managerial e-Government research themes}

The discussions raised a series of issues that can be broadly classified as concerning organisational (government) structures. Although many of them could be described as managerial, several broader questions that spread beyond single organisations emerged.

This theme raised more issues and questions than either of the other two. In contrast, the debate was more disjointed and this is reflected by the larger number of questions and categories identified (Irani \& Elliman, 2007). The main groups of issues raised included:

- interaction between and across government departments;

- coordination and ownership issues between agencies and departments;

- political engagement, policy making and the mandate to deliver automated, technology-supported services;

- project management of e-Government initiatives; in particular, change management issues;

- management of risk and knowledge so as to optimise and learn from e-Government experiences and

- metrics for measuring and evaluating organisational performance and capabilities.

Participants were concerned with the nature of eGovernment structure, agencies and their relationship to the services provided (be they informational or transactional). In particular, they saw the need to link the research work undertaken by different agencies, and academic bodies, with the needs of e-Government. Similarly local, central and European Union's e-Government policies needed to be in tune with each other. It is in this context that an agreed and stable definition of e-Government (identified in almost all of the workshops) becomes critical. 
How e-Government-related policy should be determined was discussed at length. This related to all levels of e-Government implementation, ranging from citizen-government interaction to intra-governmental departmental coordination and strategic planning of future e-Government initiatives. Identifying clear, objective and well-grounded policies were seen to be critical. Key issues related to the policy-making process were the sense of ownership that all stakeholders feel they have, the importance of 'joined up' e-Government projects, strategic planning and the organisational transformation that e-Government requires.

Closely related to this are the broader political dimensions of e-Government. Seeing e-Government services as a heuristic for engaging the citizen in the political process (eParticipation) was noted within the social theme above. Here the same question is posed, but from a managerial and organisational perspective: how should such engagement be managed? Political issues also emerged in questions like: how political processes and cycles (like the election cycle) affect the decision-making process?, and What impact does this have on e-Government strategies? Participants also questioned how much local and central government has used the e-Government agenda as a means for pursuing their own political ends.

Discussion of 'management' also raised several issues in relation to detailed management of e-Government projects. A key cultural and organisational question was that of how to cope with organisational inertia and resistance to change by senior management and other stakeholders. This relates to management of risk and failure, which were also identified as areas of concern. A particularly important area of risk was identified as an access to e-Government services and the associated issue of community inclusion (the so-called 'digital divide').

The extent to which such contingent thinking has been part of the e-Government agenda was questioned. Learning from e-Government experiences in terms of knowledge management and organisational learning was identified as another key theme. Because of the large amount of information at the core of every e-Government service, the need for effective and efficient knowledge management arose in one form or another in all of the workshops. Specifically, the issue of transferring knowledge from one context to another was deemed important.

Also, in all the workshops, it emerged that measurement and evaluation techniques were necessary for realising these learning, organisational and managerial perspectives on e-Government. In particular, the need to understand social value, identified within the social research themes above, is an important prerequisite to establishing appropriate evaluation strategies.

\section{Overarching issues}

The key findings of the VIEGO workshops can be drawn together in three groups of issues:
- Constant change is a natural occurrence in 21st century governmental institutions and it impacts people, processes and systems in equal measure. We need to understand how to create flexible systems that can adapt and change with demand. In particular, the means to manage change is critical and we must clarify the respective roles of the private and public sectors.

- Coordination and integration of inter-governmental agencies at all levels (joined-up government) is important. Their roles, processes and policies that are reflected in systems and in the interaction with stakeholders, are all fundamental to e-Government success. Coordination needs to include research and development activities, the e-Government policy-making process and to follow right through to coordinated exploitation of results.

- Lack of participation or engagement with government is a serious concern. This does not just apply to the socially excluded or even to citizens at large but to the change resistance from stakeholders throughout the system. We need to understand the factors that affect participation and to devise strategies that can produce significant internal and external changes.

Other important points to emerge are:

- E-Government is not a collection of isolated projects but an ongoing activity like human resource and treasury management. Building and maintaining a body of knowledge within and across agencies is vital.

- Shared access and the integration of resources and of ICT infrastructure are important. The ability to leverage and make best use of ICT integration standards is critical in achieving this.

- The U.K. has a rich cultural diversity and e-Government initiatives must provide the capability to capture citizen demographics and aim to stem the digital divide. This is an important prerequisite for a widespread active participation.

- Security, Privacy, Trust, Authentication and Identity management are all key issues. Not only must there be technology in place but the associated risk mitigation controls are vital.

\section{Discussions}

At first sight, prominent issues in the public debate (such as eInclusion and IT professionalism) do not surface as single top-level issues in this analysis. However, they can be found in the issue tables as cross-cutting concerns reflected in questions spread throughout the research agenda (Irani \& Elliman, 2007). In particular, the new terminology Transformational Government does not emerge as a specific topic because, like e-Government, it is in effect an umbrella for the entire research agenda.

It is difficult to promote any meaningful well-founded research without first exploring the impact and value of e-Government initiatives. Although the need for financial efficiency was recognised, government is fundamentally a social activity. Hence, there is a need to understand 
the social value of government action; the impact of e-Government systems and the way they contribute 'social value'. At a deeper level, we also need to understand how e-Goverment - in particular e-Participation is changing social structures and the implications for good governance.

Findings from all the VIEGO workshops indicate that the themes with which various stakeholders are preoccupied oscillate around a common core. All participants were interested in getting a clearer view of what users of e-Government services want, how to provide e-Government services and how they may be evaluated and measured. This understanding is essential for the design meaningful policies. Figure 5 shows the resulting key research foci that emerge from the VIEGO consultation process. These show specific components of Technology, Society, Methods and Agency (i.e. governmental body) as factors, which can provide a basis for redefining the remit of e-Government research.

Despite the fact that these findings are placed within certain categories for analytical purposes, the four areas of interest are very closely interlinked. E-Government issues have to be approached from an essentially interdisciplinary perspective and seek active engagement from all relevant stakeholders across these given areas.

Indeed, an interdisciplinary approach is necessary to encompass citizen needs and requirements in light of constant organisational, technical and social change. The need is to develop organisational, policy and technological structures that are capable of adapting to change and hence, research should also focus on these characteristics.

All the contributors were essentially representatives of particular stakeholder groups. These stakeholders need to have a stronger voice in the drafting of e-Government policies and the development of the relevant technologies. The debate regarding participation has to be linked to multiple issues, such as:

(a) technology (in the sense of the basic infrastructure that needs to be in place);

(b) education and training (the knowledge the citizens should have in order to be able to use this technology) and

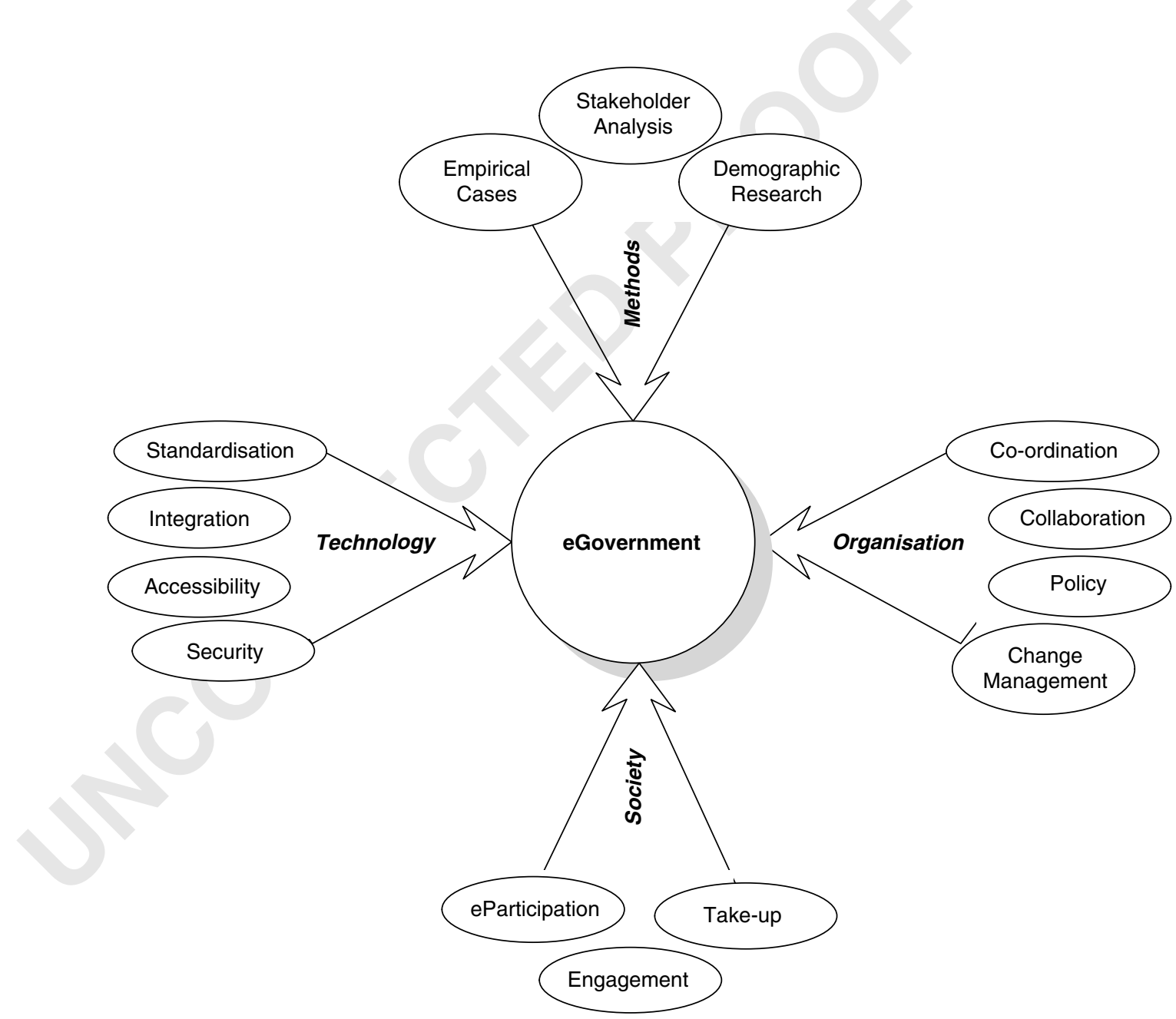

Figure 5 e-Government research foci. 
(c) organisation (the kind of managerial structures that need to be in place so that these services reach the citizen in the best possible way).

Participants also highlighted the need to view e-Government from the perspective of the entities providing the services. This specifically needs to address coordination of existing government operations or processes, and how they should be organised. The following issues are crucial:

(a) The need to deal with conflicting regulatory requirements, each following different policy rationales (deriving from national, regional or European levels).

(b) The need to cope with an increasing influx of information and the consequential need for increased risk management effort (proliferation of data results in additional resource load, leading to the risks that regulations may be overlooked and violated and due process may be impeded).

The close links, and hence the need for integration and standardisation, between organisational, social, technological and regulatory levels of e-Government projects has been underlined by the participants. This starts with the basic issue of being able to share data and technologies between local governments, or between local and central government or the central governments of different European Union Member States. None of this would be really possible without the existence of a common set of processes and data formats. Better collaboration and coordination of knowledge arising from e-Government initiatives needs to be established between and among e-Government stakeholders at all levels.

\section{Conclusions}

In conclusion, the research questions coming from eGovernment stakeholders appear to involve complex social and managerial issues driving technological elements or research. In addition, there seems to be a general consensus that existing e-Government activities remain to be evaluated and measured in order to better design future services. The use of consensus impact and focus from citizen stakeholder groups within such evaluations is essential. Clearly, the consultation workshops have shown that there are more questions raised than can be answered. Future research agendas, which expand upon the results of these VIEGO consultations, should seek to explore and provide more depth to our understanding of the issues identified.

Throughout this paper, the issues are presented as closely as possible to the questions and concerns expressed during the VIEGO workshops. In this paper, we have not attempted to assess the current start of the art or whether research unknown to the workshop participants already makes a significant contribution to solving the problem. This does not invalidate the inclusion of the topic as a research issue for VIEGO because the evidence shows that it is still necessary to incorporate the idea into mainstream thinking. If such work does exist in academic literature then VIEGO at least needs to address issues of relevance and dissemination (technology transfer) to make it effective as a working tool.

Furthermore, as a multi-stage ongoing research initiative, the second phase of project VIEGO will utilise the analysis of the findings of the workshops, which will then support the formation of and the research plans for the Virtual Institute. The agenda and plans will go to the EPSRC in a bid for research funding in 2007.

\section{Acknowledgements}

The authors wish to express their thanks to the U.K.'s Engineering Physical Sciences Research Council (EPSRC) for providing financial support for the research (grant EP/ D043840/1) and to Paul Jackson of the Chartered Institute of Public Finance and Accountancy (CIPFA)'s Improvement Through Technology Network for hosting the London meetings and chairing all five of the workshops. Finally, they wish to thank Omiros D. Sarikas, Vasiliki Mantzana and Prodromos Tsiavos for their work in painstakingly recording and analysing the workshop sessions.

\section{About the authors}

Zahir Irani is Professor of Information Systems Evaluation and Head of the Business School at Brunel University (U.K.). Having worked for several years as a project manager, he retains close links with industry. He consulted for what was the Office of the Deputy Prime Minister (ODPM) in the U.K. as well as international organisations such as HSBC, Royal Dutch Shell Petroleum, BMW and Adidas. He reviews research proposals submitted to U.K. funding councils, European Commission and the National Science Foundation (NSF) in the

U.S.A. He has been recognised as the Hooker Distinguished Professor at McMaster University (Canada) as well as being a Visiting Professor in several universities. Tony Elliman graduated as an electrical engineer before becoming a computer science lecturer in 1972. He gained his doctorate for research in medical information systems in 1989 and is now a reader in information systems and computing at Brunel University (U.K.). His research interests are in the architecture and evaluation of information systems within the public sector and in 
particular, the development of systems for professional users. He is currently the project coordinator for an EU FP6 eInclusion project DIADEM and a co-chair for the EPSRC-supported Network eGISE. He is a regular conference chair and serves on the editorial boards of the Journal of Enterprise Information Systems and Transforming Government. As a chartered engineer and chartered IT professional, he has provided software consultancy services to government, academic and private sector organisations, including DERA and the EU.

\section{References}

EUROPEAN COMMISSION (EC) (2005a) EU: U.K. government continues to lead ICT spending in Europe, IDABC: European eGovernment News Roundup, Issue 99: pp 7-8, 07 June 2005, URL: http://ec.europa.eu/ idabc/servlets/Doc?id = 21677 (accessed 1 August 2007).

EUROPEAN COMMISSION (EC) (2005b) eGovernment in the United Kingdom, June 2005, URL: http://europa.eu.int/idabc/servlets/Doc? $\mathrm{id}=21032$ (accessed 1 August 2007).

ELLIMAN T, IRANI Z and JACKSON P (2007a) Developing the eGovernment research agenda. European and Mediterranean Conference on Information Systems (EMCIS), June, 25-26, Valencia, Spain.

ELLIMAN T, IRANI Z and JACKSON P (2007b) Establishing a framework for eGovernment research: project VIEGO, Transforming Government: People, Process and Policy (accepted).
Paul Jackson is Lead Advisor on IT and e-Government at the Charted Institute of Public Finance and Accountancy (CIPFA). His key area of focus is the role of information and communications technologies (ICTs) in public service improvement. He has spent the last 5 years helping local authorities and other public bodies address the challenges bound up with delivering the e-Government and Transformational Government agendas. He comes from a background in business management and IT. He has produced five books on topics ranging from the Social Dynamics of Virtual Working to e-Business Fundamentals.

GERSHON P (2004) Gershon report: releasing resources to the front line independent review of public sector efficiency. URL: http://www. hm-treasury.gov.uk./media/C/A/efficiency_review120704.pdf (accessed 1 August 2007).

IRANI Z and ELLIMAN T (2007) Project VIEGO: towards a virtual institute for research into eGovernment. Brunel University Report, London, ISBN 978-1-902316-53-6, URL: http://www. iseing.org/iseing/Resources/VIEGO\%20Report.pdf (accessed 1 August 2007).

YILDIZ M (2007) E-government research: reviewing the literature, limitations, and ways forward. Government Information Quarterly 24, 646-665, doi:10.1016/j.giq.2007.01.002 (accessed 1 August 2007). 